\title{
Proceeding
}

Supplementary Issue: Winter Conferences of Sports Science. Costa Blanca Sports Science Events, 22-23 March 2021. Alicante, Spain.

\section{Do boxing athletes differ from controls in visually analysing opponent's postures? A pilot study tracking eye movements}

\author{
ALESSIA TESSARI ${ }^{1} \triangle$, LUISA LUGLI², ROBERTO NICOLETTI², PAOLA RICCIARDELLI ${ }^{3}$ \\ ${ }^{1}$ Department of Psychology, University of Bologna, Italy \\ ${ }^{2}$ Department of Philosophy and Communication, University of Bologna, Italy \\ ${ }^{3}$ Department of Psychology, University of Milano-Bicocca, Italy
}

\begin{abstract}
Boxing athletes code the opponents' intention to act in advance to plan and perform the most appropriate counterattack responses; in contrast, non-athletes respond with a defence action (Ottoboni, Russo, Tessari, 2015). We investigated whether such difference is limited at elaborating the most appropriate motor response or relies on different visual and attentional strategies during the early visual analysis of the opponent. We recorded saccades as indexes of visual attentional orienting during an implicit paradigm (i.e., a Simon-like task): nine experienced boxers and nine controls observed photographs of boxing attacks (jab and cross) or a neutral position (guard) and judged the colour of body parts either salient or not for elaborating the attack action (gloves vs. shorts, respectively) by shifting their gaze towards one of two lateral response boxes. Release reaction times (i.e., time between the start of the first saccade away from the fixation rectangle toward the response box) were faster toward the arm that seemed about to attack for the jab stance (the most dynamic one as implying motion) when judging the glove colour in both athletes and controls. No effect emerged when focusing on the shorts that provide irrelevant information for elaborating a defence or attack action. Therefore, athletes and controls seem to use the same visual strategies (saccadic movements) when analysing the opponent's posture before acting. However, if expertise brings better motor response processing as previously found, the difference between athletes and non-athletes must lay in a later cognitive stage (other than the visual one) devoted to plane the most effective motor response.
\end{abstract}

Keywords: Boxing; Action prediction; Eye movements; Saccade; Postures; Attention.

\section{Cite this article as:}

Tessari, A., Lugli, L., Nicoletti, R., \& Ricciardelli, P. (2021). Do boxing athletes differ from controls in visually analysing opponent's postures? A pilot study tracking eye movements. Journal of Human Sport and Exercise, 16(3proc), S996S1005. https://doi.org/10.14198/hihse.2021.16.Proc3.16

Corresponding author. Department of Psychology, University of Bologna, Italy. https://orcid.org/0000-0002-6616-2454

E-mail: alessia.tessari@unibo.it

Abstract submitted to: Winter Conferences of Sports Science. Costa Blanca Sports Science Events, 22-23 March 2021. Alicante, Spain.

JOURNAL OF HUMAN SPORT \& EXERCISE ISSN 1988-5202.

(c) Faculty of Education. University of Alicante.

doi:10.14198/jhse.2021.16.Proc3.16 


\section{INTRODUCTION}

In many sports, especially open skill ones, where the environment is constantly changing and partially unpredictable, selecting the relevant stimuli and understanding others' actions is crucial. Cognitive-perceptual skills such as attention and visual discrimination are essential to make the correct decision (Mann, Williams, Ward \& Janelle, 2007; Marteniuk, 1976). In addition, body analysis plays an essential role in reacting adequately to the environment, and each athlete must shift their attention to the most useful part of the opponent's body or of teammates to understand their future actions. To this aim, open-skill sports athletes (such as basketball or football) are able to analyse and recognize even the slightest kinematic index of the body, well before any action is taken (Aglioti, Cesari, Romani, \& Urgesi, 2008; Broadbent, Causer \& Williams, 2015; Williams \& Ford, 2013). In general, previous studies show that experts have better perceptual-cognitive abilities than non-experts (Aglioti et al., 2008; Mori et al., 2002; Petri et al., 2017; Rosalie \& Muller, 2013, 2014) and can code the kinematic movements of the opponent before an attack is released, based on automatic and implicit analysis of the opponents' body movements (e.g., Aglioti et al, 2008; Ottoboni, Russo, Tessari, 2015; Tomasino, Maieron, Guatto, Fabbro, \& Rumiati, 2013).

In particular, combat sports athletes (e.g., boxing, karate, taekwondo) not only must understand their environment as quickly as possible but also the intention to act by an opponent, in order to plan and perform the most appropriate responses to their opponent's actions, such as defence or counterattack. These athletes code the opponents' movements before these movements/actions are entirely performed (Rosalie \& Muller, 2014) so as to plan the most appropriate action to respond to them (Ottoboni et al., 2015). A study on boxers used a Simon-like paradigm (Simon, 1969) and compared experienced boxing athletes with novice boxing athletes and non-athletes while watching boxing attacks (Ottoboni et al., 2015). The results showed that experienced boxing athletes had motor pre-activation for counterattack responses and were more accurate at responding with the contralateral limb to the attack shown in the stimuli. In contrast, novice boxing athletes and non-athletes were more accurate at responding with the limb ipsilateral to the attack, like in a defence action. Novice boxing athletes simulate a defensive action on the vision of an attack action, as they are typically taught at the beginning of their training and similarly to non-athletes (Tessari, Ottoboni, Mazzatenta, Merla \& Nicoletti, 2012). Experienced boxers took longer to analyse their opponent's body posture (longer RTs), but they moved attention to cues coming from their opponent's body posture and movements (e.g., the arm that is going to attack next) as boxing coaches usually recommend: to pay close attention to cues coming from their opponent's body posture and movements, as these suggest how to plan the most effective responses in advance (see Kärrlander, 2010 for details about boxing training).

A study conducted on experienced karate athletes showed that they were faster and more precise than beginners in defending themselves or counterattacking and responding (Milazzo, Farrow \& Fournier, 2016). Interestingly, the authors also recorded eye movements to study the visual search strategy and showed that experts executed fewer fixations for a longer time and mainly on the limb and pelvis, compared to the inexperienced athletes who observed the head and torso more. Another study compared the visual search behaviour in experienced vs. inexperienced athletes in judo during the real action of knocking down the opponent by grabbing them by the collar. Experts performed few but long fixations on the opponent's lapel and face, while novices performed many short fixations on the opponent's arm (Piras, Lobietti \& Squattrito, 2014). These results are in line with those studies showing how combat sports experts adopt the strategy to anchor the gaze in mid-body areas of the opponents (e.g., Milazzo et al., 2016; Piras et al., 2014; Ripoll et al., 1995; Williams \& Elliott, 1999), or on areas of the visual field between two consecutive actions (Nougier et al., 1989). These visual strategies allow athletes to quickly shift their attention to areas of the body that are most relevant to both attacks and events in general. In general, combat sports athletes make fewer fixations 
over key areas but look at them longer (Mann et al., 2007). Conversely, in other open skill sports such as volleyball and soccer, athletes pay more attention to the areas of the space where the action of their sport typically occurs (respectively in the upper and lower visual fields; Castiello \& Umilta, 1987; Vater, Williams, \& Hossner, 2019). Therefore, it seems that eye movement behaviour in experts may account for the different visual strategies and motor behaviour that characterized these athletes compared to novices and nonathletes.

However, all the above-mentioned studies using eye movement recordings investigated fixation and did not concentrate on automatic orienting of attention in space and on visual stimuli. In contrast, it is worth mentioning that some recent eye-tracking studies focused on the investigation of the well know Simon effect, that is the phenomenon for which participants' performance is influenced by the automatic discrimination of the spatial dimension of the stimulus, even when irrelevant for the task (e.g., D'Ascenzo, Lugli, Nicoletti \& Umiltà, 2020; Lugli, Baroni, Nicoletti \& Umiltà, 2016; Verghese, Mattingley, Palmer, \& Dux, 2017). Such an effect, in fact, can be accounted for by the automatic orienting of spatial attention (e.g., Rubichi et al., 1997) and it has been considered a useful means to investigate attention, space and body representation as well as the cognitive representation of intentional action (e.g., Hommel, 2011). The above-mentioned eye-tracking studies showed that ocular responses lead to a sustained Simon effect also when the automatic orienting of attention required, not only to program a saccade but also to perform it.

Interestingly, first saccades represent a direct index of a visual orienting of attention toward a well-defined spatial location, thus allowing us to map which part of the opponent's body attracts attention and whether or not there is a difference in the visual scan paths between expert athletes and non-athletes. In fact, it may be the case that the degree of expertise shapes and affects which body part of a given posture is scanned first because more informative of an imminent attack so as to program an effective motor response. Alternatively, it may well be the case that, instead, the degree of expertise is at play and become evident later on during the programming or the execution of the motor act.

In this study, we aimed to better understand whether the difference found between expert boxing athletes and non-athletes found in studies employing manual responses is only related to elaborating the most appropriate motor response (see Ottoboni et al., 2015) or relies on different visual and attentional processing during the first stage of visual analysis of bodily postures. To this aim, we used a Simon-like paradigm (as in Ottoboni et al., 2015) requiring ocular responses to investigate whether visual differences in the automatic processes underlying stimulus processing exist between experienced boxing athletes and non-athletes. We decided to measure eye movements as this tracking technique can allow us to collect crucial information on selection and visual attentional processes (see Panchuk, Vine, \& Vickers, 2015, for an overview). Indeed, eye and manual movements are controlled by two different neural mechanisms, even though they are closely linked, in particular, there is evidence showing that eye movements and motor execution are bound (Kowler et al., 1995). However, eye movements allow us to first align objects of interest with the fovea and also to deploy attention. In fact, it has been shown a strong overlap in the brain between the neural systems for shifting attention to locations and making eye movements (Corbetta e Shulman, 2002; Grosbras et al., 2005). Specifically, fronto-parietal and temporal, cortical regions are recruited during execution of eye movements, and when we automatically orient our attention (e.g., Grosbras et al., 2005). Therefore, eye movements provide an early index of the direction of attention also conveying the intention of the looker (Spering, Schütz, Braun \& Gegenfurtner, 2011; Lisberger, 2015; Mrotek \& Soechting, 2007; Hayhoe, McKinney, Chajka \& Pelz, 2012) before the initiation of a movement. In other words, the orienting of attention would anticipate and guide the execution of an action (e.g., Rizzolatti et al., 1987; see also Smith \& Schenk, 2012 ), making the eye 
movement recordings a valuable tool to investigate possible individual differences in the visual analysis of the opponent's postures and in the orientation of attention as a function of expertise.

\section{METHOD}

\section{Participants}

Nine right-handed boxers, with normal left guard (mean age $=27.55$ years; SD: \pm 5.23 ), with at least 5 official matches, were selected for the experimental group, and nine right-handed students (mean age = 24 years; SD: \pm 2.58 ) of the University of Bologna served as a control group. All the participants had normal or correct to normal vision and voluntarily participated in the study without getting paid after written consent. The participants were all right-handed, according to the Edinburgh Inventory Test (Oldfield, 1971).

A power analysis was conducted based on Ottoboni et al., 2005 (Experiments 2A, 2B and 3), Tessari, Ottoboni, Mazzatenta, Merla \& Nicoletti (2012; Experiment 1) and Ottoboni et al. (2015). Instead of calculating the average Cohen's $D$, we have chosen the smallest one to calculate the larger sample size possible to obtain the effect. We used G*Power (Faul, Erdfelder, Lang, \& Buchner, 2007) to calculate the sample size: with an effect size Cohen's $D=1.14$ (calculated for the View $x$ Correspondence interaction), Alpha $=.05$, and Power of 0.80 , we would need 7 participants.

\section{Stimuli}

The stimuli consisted of photographs of boxing athletes executing either an attack (i.e., jab or cross) or a neutral position (i.e., guard). The photographs were in greyscale and were presented in two versions: coloured shorts or coloured gloves in either a red or a blue shade. The background was uniformed to the same shade of grey as the monitor background. See figure 1. Each image was flipped on its horizontal axis to create two matching images and counterbalance potential bias generated by the athlete's orthodox stance. Twenty-four stimuli were created overall: 12 red-coloured and 12 blue-coloured stimuli, half with coloured shorts, and the other half with coloured gloves. Each stimulus was presented 10 times for a total amount of 240 trials. Twenty-four stimuli served as test trials. Stimuli were presented randomly but in separate blocks with only the coloured short or the coloured glove versions of the stimuli. The order of the two blocks were counterbalanced between participants.
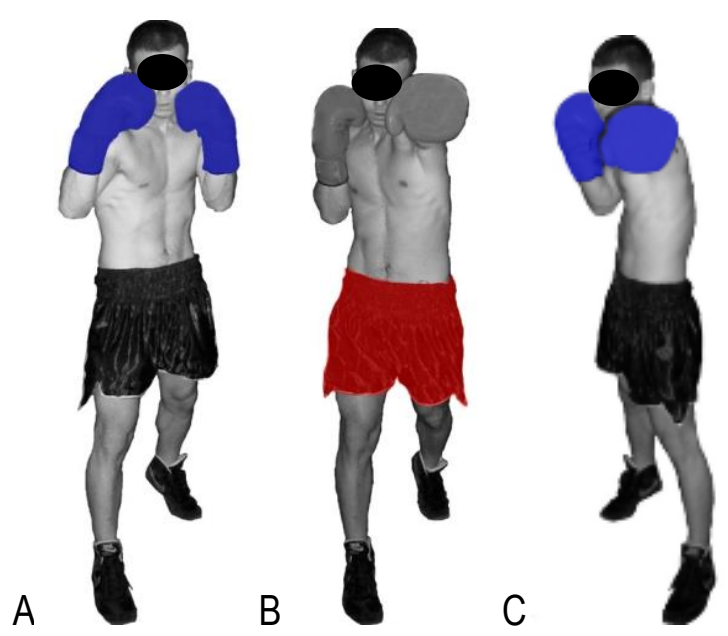

Figure 1. Example of the stimuli for both the gloves-colored and the shorts-colored condition. A represents an example of the guard stance; $B$ represents a cross stance, and $C$ represents the jab stance. 


\section{Procedure}

Participants sat in front of a 17 -inch $(1024 \times 768)$ LCD monitor controlled by a computer with a $700 \mathrm{MHz}$ processor, at a viewing distance of $70 \mathrm{~cm}$ in a dimly lit and quiet room. At the beginning of the experiment, a standard five-point eye tracker calibration routine was used. Participants' pupils were traced using an iView $X$ remote eye localization device (RED; SensoMotoric Instruments [SMI], Teltow, Germany). Data were recorded with a $500-\mathrm{Hz}$ sampling rate using the iView X (SMI) software. At the beginning of each trial, the fixation cross $(0.95 \mathrm{~L} \cdot 0.95 \mathrm{~L}$ of visual angle) and the response boxes appeared first. The fixation point was the " + " Currier New font, size 36, in bold. The fixation cross remained visible for $1000 \mathrm{~ms}$. The response boxes measured $200 \mathrm{~L} \times 150 \mathrm{H}$ (in pixel) and the screen resolution was $1280 \mathrm{~L} \times 800 \mathrm{H}$ (in pixel). The stimulus appeared immediately after the fixation point's disappearance and remained until gazes inside one of the response boxes for $1500 \mathrm{~ms}$ or a maximum of $4000 \mathrm{~ms}$. See Figure 2. Stimulus presentation, responses recording, and timing were managed using the software E-Prime ${ }^{\circledR}$ version 2.0.8.90 (see Stahl, 2006). Participants were required to judge the colour of either the gloves or the short by moving their gaze within the two lateralized response boxes. Association between response boxes and colour was counterbalanced across participants. At the beginning of the experiment, participants provided information about their ages, the dominant hand and, only for the boxing athletes, the type of stance they adopted (orthodox or southpaw) and the number of matches they had competed.
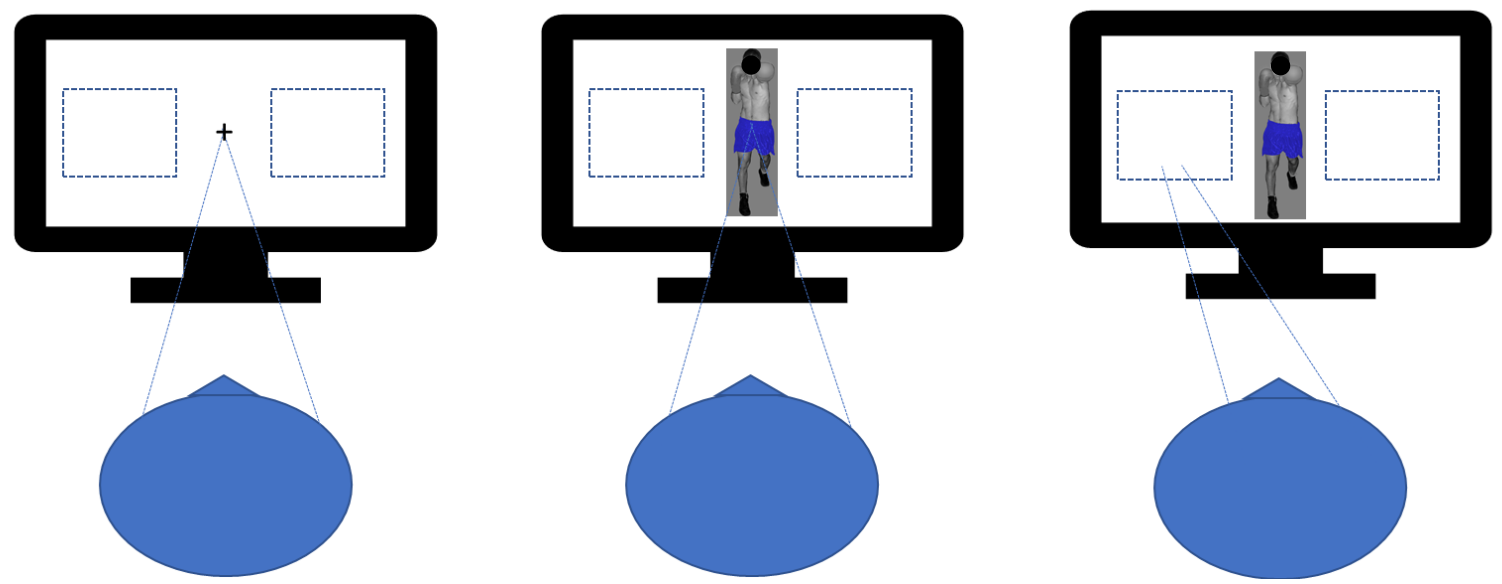

Figure 2. Visual representation of the sequence of event in a trial. A fixation appeared and the stimulus appeared immediately after the fixation point's disappearance. Then participants had to move their gaze into one of the two lateral rectangles according to the colour of the salient part of the stimulus (shorts, in this example, or gloves). The rectangle-colour association was counterbalanced across participants.

\section{Data analysis}

The data analysis was performed on response Accuracy and ReIRT, i.e., the response time from target stimulus onset to saccade toward the response rectangle onset (measured in milliseconds). Only the correct trials were analysed and ReIRTs (in $\mathrm{msec}$ ) within two standard deviations below and above each participant's average. The within-subjects factors taken into consideration were: Correspondence (corresponding vs. noncorresponding responses defined on the basis of the response side and the side where the boxer in the picture performed the attack action), Posture (jab vs. cross vs. guard), and the Coloured part (boxer vs. shorts). The between-group factor was Group (athletes vs. non-athletes). A Greenhouse-Geisser correction was applied due to a 3-levels factor and lack of sphericity in the data. 


\section{RESULTS}

As regards to RelRTs, only the triple interaction Coloured part x Posture $x$ Correspondence was significant: $F(1.54,24.70)=4.18, p=.036$. We performed separated t-test between corresponding and noncorresponding conditions and only a significant difference within the Jab condition emerged (one-tailed t-test $t(17)=2,236, p=.019$ ) when evaluating the colour of the gloves: corresponding pairing (mean $=337$; $S E=$ 28 ) were slower than the non-corresponding ones (mean $=310 ; S D=19)$. See Figure 3.

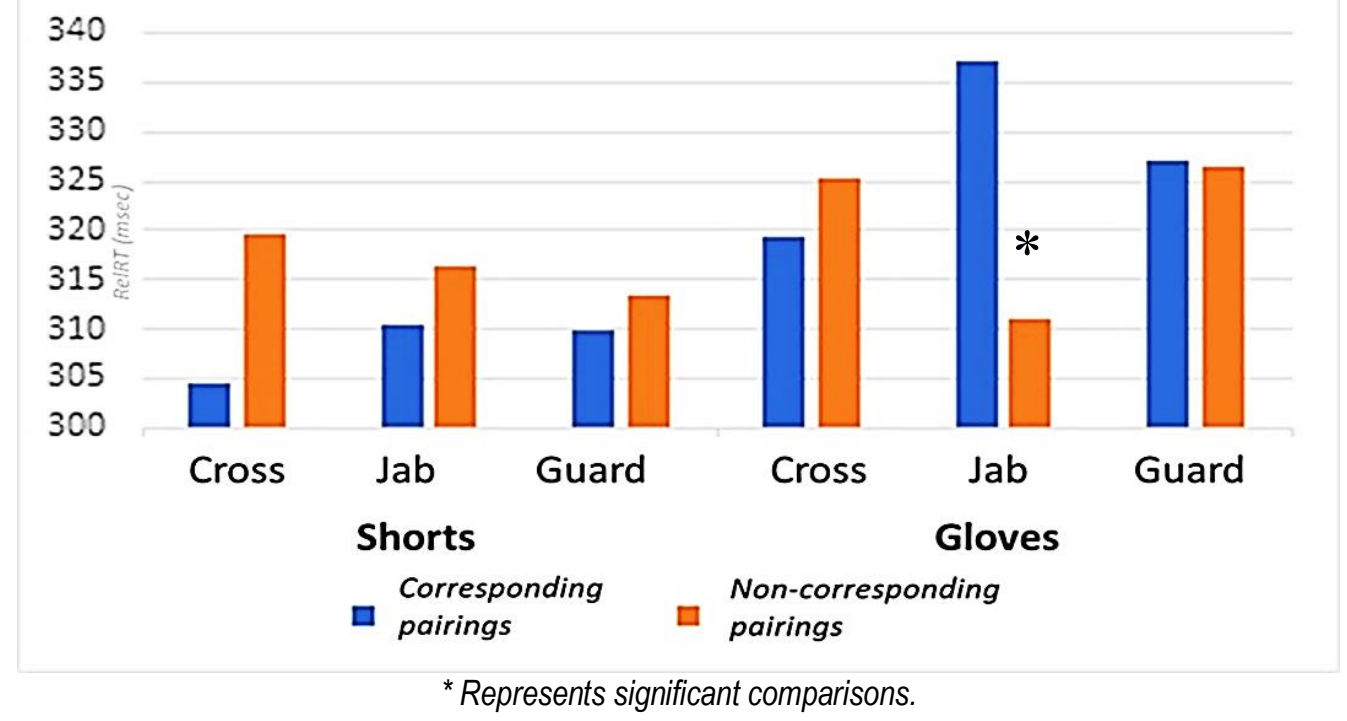

Figure 3. RelRTs (in msec) are shown according to the main factors Coloured part (shorts vs. gloves), Posture (Cross vs. Jab vs. Guard) and Correspondence (corresponding vs non-corresponding pairings).

Analysis on accuracy data revealed that both the Correspondence $(F(1,16)=5.033 p=.039)$ and the Group $(F(1,16)=7.53 p=.014)$ factors were significant. Corresponding pairings $(92.73 \%$; $S E=1.99)$ were more accurate than non-corresponding ones $(89.95 \%, \mathrm{SE}=2.05)$; and Athletes $(96.62 \%, \mathrm{SE}=2.72)$ were more accurate than controls $(86.06 \%, \mathrm{SE}=2.72)$.

\section{DISCUSSION AND CONCLUSIONS}

In this study, we tried to deepen and expand the results obtained in a previous study on expert boxing athletes (Ottoboni et al., 2015) to investigate whether they elaborated body postures differently from non-expert individuals at an early, attentive stage. In particular, we tried to understand if the different responding strategy observed in experienced athletes (i.e., preparing for a counterattacking action instead of a defence action as controls and novices do) was manifested only at the level of the motor programming of response or whether it already exists in the phase of visual analysis of the stimulus and overt orienting of visual attention.

We recorded eye movement and measured the ReIRT, i.e., the time between the start of the first saccade away from the fixation rectangle toward the correct response box. Overall, the athletes were more accurate than non-athletes in performing the task. However, expert athletes and controls behaved similarly showing a different response in the case of the jab stance compared to the other body postures. Specifically, only in the jab stance, both groups were faster in correctly responding to the colour of the gloves in the noncorresponding trials. This result can be explained with the fact that the attack action portrayed in the jab does 
not seem still concluded and participants exhibit an attentional shift towards the fist that is about to act (i.e., which is loading the next action on the non-corresponding side of the response) on the opposite side of the one who just finished to attack (on the corresponding side of the response). The jab appears more dynamic than the other stances since it transmits a higher sensation of implied movement and it is associated with and characterized by a superior emotional component. On the contrary, for example, the cross stance (see Figure 1) is probably perceived as representing an already completed attack action and does not imply an immediate contralateral blow.

However, even though both groups (athletes and controls) perceived and processed the implied movements and the potential attack action transmitted by the stimuli similarly, athletes were more accurate in executing the ocular responses and, therefore, in controlling their gaze and this might be beneficial as it provides more time to take a decision and for the adjustment of hand movements (see Fooken, Yeo, Pai \& Spering, 2016; Palidis, Wyder-Hodge, Fooken \& Spering, 2017 for similar interpretation with baseball players).

The present findings suggest that expertise can bring to a superior and better processing of response programming (Ottoboni et al., 2015 showed that expert boxers behave diametrically opposite with respect to both controls and novices) but not at the level of visual analysis of the stimulus and attentional orienting: expert athletes analysed the stimulus as the controls (this study), but the former predict the outcome of the seen attack actions and prepared adequate responses (see Ottoboni et al., 2015). Moreover, experienced athletes were more accurate in carrying out the ocular response while analysing the visual stimulus. This ability might result later in a better way of preparing movements and planning the most effective responses in advance (see Ottoboni et al, 2015 but also Kärrlander, 2010). Differences from Ottoboni's results (2015) might be explained by the fact that in their study, participants were asked to perform the task using a salient effector, i.e., the arm/hand. On the contrary, we required the participants to make their answer by moving their eyes, and therefore, different faciliatory effects have emerged. In particular, no difference in facilitatory effect has been found between athletes and controls.

It must also be emphasized that we did not collect data on fixations and did not focus on their duration, number and position as previously done in the literature (e.g., Milazzo et al., 2016; Piras et al., 2014), but we focused on an earlier stage of processing, that of the first saccades, which inform us about the processing of visual inputs and are the direct index of the orientation of visual attention.

In sports, both the motor and visual experience allow the motor system's recruitment, but only the combination of these two components allows an accurate forecast of the event in experienced elite athletes (Urgesi \& Makris, 2016). Elite athletes predict the outcomes of action in their specific domain and read the opponent's intentions through (partial) signals, which can be temporal (when they will perform an action), spatial (where they will perform it) and executive (what kind of action they will choose) (De Gelder, 2005; Ripoll, 1989). To achieve these goals, the cognitive system completes the sport-specific event by creating internal movement models, respecting the physical laws of reality, and built based on motor and visual experience. It uses topdown modulation to complete the sequence and make up for missing visual information (Komatsu 2006; Pessoa, Thompson \& Noë 1998). Therefore, the expert athletes have an anticipatory advantage consisting of two fundamental components: the collection of (visual) kinematic information from the opponent's movement model and the prediction of the visual dynamics of the actions and related contexts (Abernethy et al., 2001). Therefore, an effective performance does not depend on the peculiarities of a specific visual stimulus or motor response set but on the properties that result from the combination of both sets. Our results suggest that the differences that emerged in the response style in Ottoboni et al. (2015) do not depend on different visual analysis strategies between athletes and controls (they used the same visual strategies - 
same pattern of saccadic movements - when analysing the opponent's posture before acting). However, it seems that expertise brings a superior and better processing of response programming (Ottoboni et al., 2015). The difference between athletes and non-athletes must lay in a latter cognitive stage (other than the visual one) devoted to plane the most effective motor response (counterattack vs. defence action).

\section{REFERENCES}

Abernethy, B., Gill, D. P., Parks, S. L., \& Packer, S. T. (2001). Expertise and the perception of kinematic and situational probability information. Perception, 30(2), 233-252. https://doi.org/10.1068/p2872

Aglioti, S. M., Cesari, P., Romani, M., \& Urgesi, C. (2008). Action anticipation and motor resonance in elite basketball players. Nature neuroscience, 11(9), 1109. https://doi.org/10.1038/nn.2182

Broadbent, D. P., Causer, J., Williams, A. M., \& Ford, P. R. (2015). Perceptual-cognitive skill training and its transfer to expert performance in the field: Future research directions. European journal of sport science, 15(4), 322-331. https://doi.org/10.1080/17461391.2014.957727

Castiello, U., \& Umiltà, C. (1987). Spatial compatibility effects in different sports. International Journal of Sport Psychology.

Corbetta, M., \& Shulman, G. L. (2002). Control of goal-directed and stimulus-driven attention in the brain. Nature reviews neuroscience, 3(3), 201-215. https://doi.org/10.1038/nrn755

D'Ascenzo, S., Lugli, L., Nicoletti, R., \& Umiltà, C.A. (2020). Practice effect vs. transfer effects in the Simon task. Psychological Research. https://doi.org/10.1007/s00426-020-01386-1

de Gelder, B. (2005). Nonconscious Emotions: New Findings and Perspectives on Nonconscious Facial Expression Recognition and Its Voice and Whole-Body Contexts. In L. F. Barrett, P. M. Niedenthal, \& P. Winkielman (Eds.), Emotion and consciousness (p. 123-149). The Guilford Press.

Faul, F., Erdfelder, E., Lang, A. G., \& Buchner, A. (2007). G* Power 3: A flexible statistical power analysis program for the social, behavioral, and biomedical sciences. Behavior research methods, 39(2), 175191. https://doi.org/10.3758/BF03193146

Fooken, J., Yeo, S. H., Pai, D. K., \& Spering, M. (2016). Eye movement accuracy determines natural interception strategies. Journal of vision, 16(14), 1-1. https://doi.org/10.1167/16.14.1

Grosbras, M. H., Laird, A. R., \& Paus, T. (2005). Cortical regions involved in eye movements, shifts of attention, and gaze perception. Human brain mapping, 25(1), 140-154. https://doi.org/10.1002/hbm.20145

Hayhoe M. M, McKinney T, Chajka K, Pelz J. B. (2012). Predictive eye movements in natural vision. Experimental Brain Research, 217, 125-136. https://doi.org/10.1007/s00221-011-2979-2

Hommel, B. (2011). The Simon effect as tool and heuristic. Acta psychologica, 136(2), 189-202. https://doi.org/10.1016/j.actpsy.2010.04.011

Kärrlander, P. (2010). The complete boxing handbook: A step by step guide to boxing. Scotts Valley, CA: CreateSpace Independent Publishing Platform.

Komatsu, H. (2006). The neural mechanisms of perceptual filling-in. Nature reviews neuroscience, 7(3), 220-231. https://doi.org/10.1038/nrn1869

Kowler, E., Anderson, E., Dosher, B., \& Blaser, E. (1995). The role of attention in the programming of saccades. Vision research, 35(13), 1897-1916. https://doi.org/10.1016/0042-6989(94)00279-U

Lisberger S. G. (2015). Visual guidance of smooth pursuit eye movements. Annual Review of Vision Science, 1, 447-468. https://doi.org/10.1146/annurev-vision-082114-035349

Lugli, L., Baroni, G., Nicoletti, R., \& Umiltà, C. A. (2016). The Simon effect with saccadic eye movements. Experimental Psychology, 63, 107-116. https://doi.org/10.1027/1618-3169/a000319 
Mann,D.T.,Williams,A.M.,Ward,P.,\&Janelle,C.M.(2007).Perceptual-cognitiveexpertiseinsport:Ametaanalysis.Journal of Sport \& Exercise Psychology, 29(4),457- 478. https://doi.org/10.1123/jsep.29.4.457

Marteniuk,R.G.(1976).Information processing in motor skills.NewYork,NY:Holt,Rinehart,andWinston.

Milazzo, N., Farrow, D., Ruffault, A., \& Fournier, J. F. (2016). Do karate fighters use situational probability information to improve decision-making performance during on-mat tasks?. Journal of Sports Sciences, 34(16), 1547-1556. https://doi.org/10.1080/02640414.2015.1122824

Mori, S., Ohtani, Y., \& Imanaka, K. (2002). Reaction times and anticipatory skills of karate athletes. Human movement science, 21(2), 213-230. https://doi.org/10.1016/S0167-9457(02)00103-3

Mrotek L. A, Soechting J. F. (2007). Target interception: Hand-eye coordination and strategies. Journal of Neuroscience, 27, 7297-7309. https://doi.org/10.1523/JNEUROSCI.2046-07.2007

Nougier, V., Ripoll, H., \& Stein, J. F. (1989). Orienting of attention with highly skilled athletes. International Journal of Sport Psychology.

Ottoboni, G., Russo, G., \& Tessari, A. (2015). What boxing-related stimuli reveal about response behaviour. Journal of Sports Sciences, 33(10), 1019-1027. https://doi.org/10.1080/02640414.2014.977939

Palidis, D. J., Wyder-Hodge, P. A., Fooken, J., \& Spering, M. (2017). Distinct eye movement patterns enhance dynamic visual acuity. Plos one, 12(2), e0172061. https://doi.org/10.1371/journal.pone.0172061

Panchuk, D., Vine, S., \& Vickers, J. N. (2015). Eye tracking methods in sport expertise. Routledge handbook of sport expertise, 176-187. https://doi.org/10.4324/9781315776675-16

Pessoa, L., Thompson, E., \& Noë, A. (1998). Finding out about filling-in: A guide to perceptual completion for visual science and the philosophy of perception. Behavioral and brain sciences, 21(6), 723-748. https://doi.org/10.1017/S0140525X98001757

Petri, K., Lichtenstein, M., Bandow, N., Campe, S., Wechselberger, M., Sprenger, D., ... \& Witte, K. (2017). Analysis of anticipation by 3D motion capturing-a new method presented in karate kumite. Journal of Sports Sciences, 35(2), 130-135. https://doi.org/10.1080/02640414.2016.1158851

Piras, A., Pierantozzi, E., \& Squatrito, S. (2014). Visual search strategy in judo fighters during the execution of the first grip. International Journal of Sports Science \& Coaching, 9(1), 185-198. https://doi.org/10.1260/1747-9541.9.1.185

Ripoll, H. (1989). Uncertainty and visual strategies in table tennis. Perceptual and motor skills, 68(2), 507-512. https://doi.org/10.2466/pms.1989.68.2.507

Ripoll, H., Kerlirzin, Y., Stein, J. F., \& Reine, B. (1995). Analysis of information processing, decision making, and visual strategies in complex problem solving sport situations. Human Movement Science, 14(3), 325-349. https://doi.org/10.1016/0167-9457(95)00019-0

Rizzolatti, G., Riggio, L., Dascola, I., \& Umiltá, C. (1987). Reorienting attention across the horizontal and vertical meridians: evidence in favor of a premotor theory of attention. Neuropsychologia, 25(1), 3140. https://doi.org/10.1016/0028-3932(87)90041-8

Rosalie, S. M., \& Müller, S. (2013). Timing of in situ visual information pick-up that differentiates expert and near-expert anticipation in a complex motor skill. Quarterly journal of experimental psychology, 66(10), 1951-1962. https://doi.org/10.1080/17470218.2013.770044

Rosalie, S. M., \& Müller, S. (2014). Expertise facilitates the transfer of anticipation skill across domains. Quarterly Journal of Experimental Psychology, 67(2), 319-334. https://doi.org/10.1080/17470218.2013.807856

Rubichi, S., Nicoletti, R., lani, C., \& Umiltà, C. (1997). The Simon effect occurs relative to the direction of an attention shift. Journal of Experimental Psychology: Human Perception and Performance, 23(5), 1353-1364. https://doi.org/10.1037/0096-1523.23.5.1353 
Simon, J. R. (1969). Reactions toward the source of stimulation. Journal of experimental psychology, 81(1), 174. https://doi.org/10.1037/h0027448

Smith, D. T., \& Schenk, T. (2012). The premotor theory of attention: time to move on?. Neuropsychologia, 50(6), 1104-1114. https://doi.org/10.1016/i.neuropsychologia.2012.01.025

Spering M, Schütz A. C, Braun D. I, Gegenfurtner K. R. (2011). Keep your eyes on the ball: Smooth pursuit eye movements enhance prediction of visual motion. Journal of Neurophysiology, 105, 17561767. https://doi.org/10.1152/jin.00344.2010

Tessari, A., Ottoboni, G., Mazzatenta, A., Merla, A., \& Nicoletti, R. (2012). Please don't! The automatic extrapolation of dangerous intentions. PLoS One, 7(11), e49011. https://doi.org/10.1371/journal.pone.0049011

Tomasino, B., Maieron, M., Guatto, E., Fabbro, F., \& Rumiati, R. I. (2013). How are the motor system activity and functional connectivity between the cognitive and sensorimotor systems modulated by athletic expertise?. Brain research, 1540, 21-41. https://doi.org/10.1016/..brainres.2013.09.048

Urgesi, C., \& Makris, S. (2016). Sport performance: Motor expertise and observational learning in sport.

Vater, C., Williams, A. M., \& Hossner, E. J. (2020). What do we see out of the corner of our eye? The role of visual pivots and gaze anchors in sport. International Review of Sport and Exercise Psychology, 13(1), 81-103. https://doi.org/10.1080/1750984X.2019.1582082

Verghese, A., Mattingley, J. B., Palmer, P. E., \& Dux, P. E. (2017). From eyes to hands: Transfer of learning in the Simon task across motor effectors. Attention, Perception, and Psychophysics., 17,118. https://doi.org/10.3758/s13414-017-1427-1

Williams, A. M., \& Elliott, D. (1999). Anxiety, expertise, and visual search strategy in karate. Journal of Sport and Exercise Psychology, 21(4), 362-375. https://doi.org/10.1123//sep.21.4.362

Williams, A. M., \& Ford, P. R. (2013). Game intelligence': anticipation and decision making. Science and soccer: Developing elite performers, 105-121.

\section{@) $\oplus \Theta \Theta$}

This work is licensed under a Attribution-NonCommercial-NoDerivatives 4.0 International (CC BY-NC-ND 4.0). 